\title{
Distinct cross-shelf gradient in mesophotic reef fish assemblages in subtropical eastern Australia
}

\author{
Ryan Pearson*, Tim Stevens \\ Griffith School of Environment and Australian Rivers Institute, Gold Coast campus, Griffith University, Queensland 4222, \\ Australia
}

\begin{abstract}
The hypothesized importance of mesophotic (30 to $150 \mathrm{~m}$ depth) reefs justifies the recent trend in scientific scrutiny of these systems. However, to enable assessment of complex concepts such as connectivity and reef dynamics, baseline assemblage characteristics must first be established. This study used baited remote underwater video (BRUV) technology to investigate the assemblage structure of predatory and scavenging fishes across 4 mesophotic reef bands at ca. 30 to $82 \mathrm{~m}$ depth, at 2 locations $25 \mathrm{~km}$ apart in subtropical eastern Australia. We aimed to quantify patterns in predatory and scavenging fish assemblage structure at these reefs across the continental shelf and relate this to putative structuring environmental variables. Strong cross-shelf gradients were identified in species richness and overall assemblage composition. While the pattern of latitudinal affiliation did not change across the shelf, predatory and scavenging fish assemblages at non-adjacent reefs were statistically distinct (PERMANOVA interaction term $p=0.012$ ), and best (but not well) explained by depth alone (BIOENV $\rho=0.396)$. A high proportion (15 to $45 \%$ ) of the fish species at each reef band were found only within that band. These cross-shelf trends contrasted with those described from more complex shelf topography such as at the Solitary Islands (250 km south), and did not match published patterns of epibenthic assemblage structure. Our results highlight the need for detailed information on mesophotic reef assemblage structure to support marine conservation and reserve design initiatives, rather than relying on generalised trends from the literature.
\end{abstract}

KEY WORDS: Mesophotic reefs $\cdot$ Subtropical fish $\cdot$ Predator assemblage $\cdot$ Drivers

\section{INTRODUCTION}

Marine ecosystems worldwide are under wellpublicised anthropogenic threats (Hoegh-Guldberg 1999, Hughes et al. 2003, Halpern et al. 2012) that can have strong impacts on marine biodiversity and overall system resilience by impacting the various ecosystem services that biodiversity provides (Duffy 2002). Species within upper trophic levels help to maintain biodiversity and mediate competition (Hixon \& Carr 1997) by the top-down process of selective predation, but also tend to be key fishery targets.

The roles of these higher trophic level fish taxa in structuring shallow water $(<30 \mathrm{~m})$ ecosystems through competition, predation, and scavenging are relatively well studied, especially on coral reefs (e.g. McClanahan 1995, Hixon \& Carr 1997, Sala 1997, Gomelyuk 2009). However, the influence of these processes on deeper reefs is poorly known, in part because of the cost and logistical difficulties associated with working in areas beyond the practical range of standard SCUBA equipment. In recent years, advances in lowcost and lightweight camera equipment, as well as in diving technology, have helped to fuel growing interest in the ecology of reefs in the mesophotic zone (30 to $150 \mathrm{~m}$ depth) (Hughes et al. 2003, Riegl \& Piller 2003, Lesser et al. 2009, Puglise et al. 2009, Edgar et al. 2010). Tropical shallow water reefal species may be able to use reefs in the mesophotic zone and/or subtropical reefs as refuges in the face of anthro- 
pogenic and climate related challenges (Hughes et al. 2003, Riegl \& Piller 2003, Bongaerts et al. 2010, Kahng et al. 2014). Mesophotic reefs may also harbour their own unique assemblages, with high levels of depthendemism reported across multiple taxa, including corals (e.g. Bridge et al. 2012) and fishes (e.g. Pyle et al. 2008, Kane et al. 2014).

Mesophotic reef systems may also play an important role in marine ecosystem dynamics, resilience, and connectivity (Puglise et al. 2009, Tenggardjaja et al. 2014), in ways as yet poorly understood, though some patterns appear consistent. Vertical differences in mesophotic fauna are well established (Kahng et al. 2010, 2014). A transition between characteristic upper and lower mesophotic assemblages in the tropics has been reported at ca. $60 \mathrm{~m}$ (e.g. Bridge et al. 2012), and at ca. $50 \mathrm{~m}$ in the subtropics (e.g. Malcolm et al. 2010b). Despite these apparent transitions in assemblage structure, Tenggardjaja et al. (2014) found no obvious genetic differences between more than 400 Chromis verater specimens collected at shallow and mesophotic reefs (to $113 \mathrm{~m}$ ) in Hawaii, supporting hypotheses inferring high vertical connectivity and deep refugia. There are also documented links between epibenthic and fish assemblages in the mesophotic zone (Brokovich et al. 2010, Malcolm et al. 2011b), but the strength of this association varies.

A handful of studies have highlighted specific trends in the cross-shelf assemblages of fishes, molluscs, and corals within the eastern Australian subtropics (Edgar et al. 2010, Malcolm et al. 2010a,b, 2011a,b, Harrison \& Smith 2012). Most notably, consistent trends exist across all tested taxa in the Solitary Islands Marine Park (SIMP), where the proportion of tropical species increases with distance from shore on shallow reefs (Malcolm et al. 2007, 2010a, Harrison \& Smith 2012) but decreases with depth (Malcolm et al. 2011b). The shallow water trends may be driven by the variable influence of conflicting water bodies in the region. The warm East Australian Current (EAC), which flows south along the continental shelf edge, operates mostly offshore in the SIMP and is subject to regular seasonal changes that affect its flow rate, width, and southern extent (Keane \& Neira 2008). Inshore however, cooler counter-currents run northward along the coastline, in the opposite direction to the EAC. This creates 3 latitudinally distinct water bodies along the east coast, which correspond well with larval fish assemblages (Keane \& Neira 2008, Neira \& Keane 2008). The current study area in southeast Queensland (QLD) and northeast New South Wales (NSW) lies consistently within the most northern, largely EACinfluenced water body (Neira \& Keane 2008). Within this region, the distribution of reef biota is poorly known (Richmond \& Stevens 2014), and no quantitative studies have examined mesophotic fish assemblages or their relationship to the characteristics of the water body.

Therefore, this study aims to (1) classify and test patterns in predatory and scavenging fish assemblages on mesophotic reefs across the continental shelf of subtropical eastern Australia; (2) evaluate differences in the latitudinal affiliations of derived fish assemblages across the continental shelf for comparison with trends noted elsewhere (especially in the SIMP); and (3) quantify the role of environmental drivers in structuring these assemblages.

\section{MATERIALS AND METHODS}

\section{Study area}

The Southport Seaway and Tweed River mouth are key entry points to ocean waters, situated 65 and $93 \mathrm{~km}$, respectively, south of Brisbane in the vicinity of the Gold Coast on the east coast of Australia. Several discontinuous bands of rocky reef are found from ca. 3 to $35 \mathrm{~km}$ seaward of the Gold Coast, in depths of 30 to $82 \mathrm{~m}$. These are well known to local recreational and commercial fishers, but have received little scientific attention (Richmond \& Stevens 2014), and have not been accurately mapped.

\section{Sampling design}

Sampling of predator and scavenger assemblage structure was conducted in winter 2013 using baited remote underwater video (BRUV) deployed for 30 min at 4 bands of rocky reef across the continental shelf directly east of the Southport Seaway $\left(153^{\circ} 25^{\prime} \mathrm{E}\right.$, $\left.27^{\circ} 56^{\prime} \mathrm{S}\right)$ and Tweed River mouth $\left(153^{\circ} 33^{\prime} \mathrm{E}, 28^{\circ} 10^{\prime} \mathrm{S}\right)$ (Fig. 1). The BRUV method has known biases in that it attracts predatory and scavenging species and under-represents herbivores (see Colton \& Swearer 2010 for example); nevertheless, it is acknowledged as one of the most precise methods available for fish abundance surveys (Bernard \& Götz 2012) since it is not affected by diver avoidance or errors associated with various capture techniques. Moreover, it is lowimpact and useable at any depth, on any substrate. Throughout this paper (unless otherwise stated), we refer to the predatory and scavenging reef fish as- 


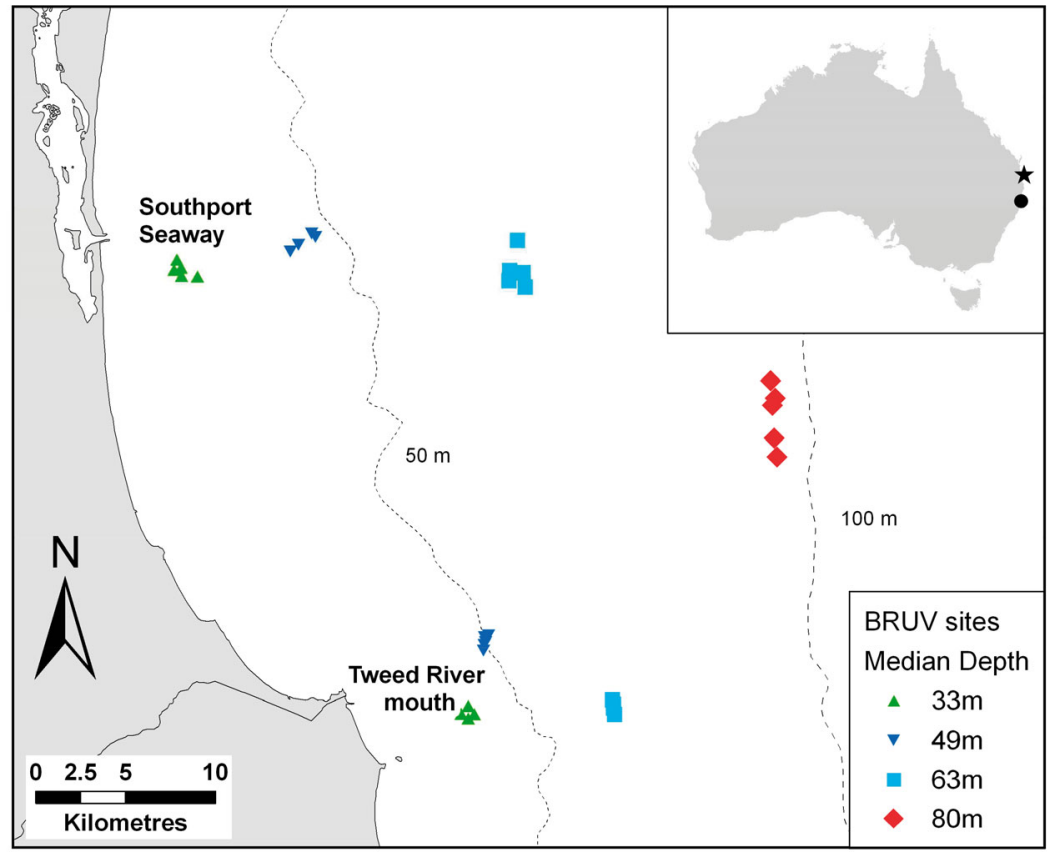

Fig. 1. Study area and sampling sites at Southport Seaway and Tweed River locations. The star in the inset map shows the study position, while the dot shows Solitary Islands Marine Park (SIMP). BRUV: baited remote underwater video

iTorch 5 LED video lights to provide accurate and consistent colour information for species identification. Two $5 \mathrm{~cm}$ squares of Perspex (white with a black border to aid visibility) were attached to the bait pole, $15 \mathrm{~cm}$ apart on either side of the bait bag. These were used to estimate the size of a fish at the bait bag. The change in size on screen of this same individual was then used to estimate a distance ca. $2 \mathrm{~m}$ behind the bait bag to standardise the sampled volume for variations in water clarity between deployments, and to estimate distance from the bait bag for adjacent habitat descriptors as per Cappo et al. (2004).

All deployments were analysed by the same observer, and maxN recorded for each species; with MaxN defined as the highest number of individuals of a given species visible within a single frame of video throughout each $30 \mathrm{~min}$ deployment (Malcolm et al. 2011b). Individuals were identified to the finest

semblage sampled by this technique (Cappo et al. 2004).

The depth range for the reef bands sampled was as follows: band 1,30 to $34 \mathrm{~m}$ depth (median $33 \mathrm{~m}$ ); band 2, 46 to $51 \mathrm{~m}$ (median $49 \mathrm{~m}$ ); band 3, 62 to $65 \mathrm{~m}$ (median $63 \mathrm{~m}$ ); and band 4, 79 to $82 \mathrm{~m}$ (median $80 \mathrm{~m}$ ). We use the median depth figures to refer to the reef bands throughout the paper (Fig. 1). At the deepest band, we were not able to locate reef offshore from the Tweed River mouth, so the design is unbalanced in this respect. Analyses were interpreted with this in mind, with most weight placed on the pairwise contrasts.

Waypoint data (not shown) obtained from the local charter fishing association was used to locate the reefs, and then BRUVs were deployed on reef patches with a linear extent of more than $200 \mathrm{~m}$ (estimated using the onboard echo sounder) to minimise bias associated with variation in reef patch size. At each site, nominally 5 replicate BRUVs were deployed in rotation for $30 \mathrm{~min}$ each, spaced at least $500 \mathrm{~m}$ apart to minimise overlap between bait plumes (Willis \& Babcock 2000, Harvey et al. 2007, Colton \& Swearer 2010). Each rig was baited with 2 pilchards Sardinops sagax (ca. $100 \mathrm{~g}$ ) in the bait bag; one cut into 5 equal sections and the other placed into a nylon stocking and crushed to maximise release of oils. Each deployment was recorded on a GoPro2 camera with 2 level of taxonomic classification possible using standard and locally relevant guides, principally Kuiter (1996), Allen et al. (2003), Allen (2009), and Davie et al. (2011) as well as online sources www.fishbase.org and http://australianmuseum.net.au.

\section{Drivers for assemblage structure}

Data on a range of putative drivers for fish assemblage structure were collected or assembled from existing data sources (Table 1). Temperature and salinity data were measured in situ using a conductivity, temperature and depth (CTD) probe (model RBR XR-420, CTD Marine) deployed simultaneously with the BRUVs. Incident light levels were assessed on most of the deployments (25 of 32; see 'Results') using a HOBO Pendant temperature and light logger (Model UA-002-64) attached to the CTD. Light intensity (in lux) was averaged over $30 \mathrm{~s}$ at the top (ca. $2 \mathrm{~m}$ depth) and bottom (ca. $2 \mathrm{~m}$ above the substrate, to avoid any disturbed sediment) of the water column, and used to calculate percentage light intensity remaining at the bottom.

Geographic attributes to assess the influence of land- or river-sourced inputs (distance from shore and distance to the nearest estuary) were derived using GIS software (ArcGIS v.9.2). Attributes of the 
Table 1. Putative drivers for predator and scavenger fish assemblage structure

\begin{tabular}{|c|c|c|}
\hline Driver & Source & Units \\
\hline Depth & On-board echo sounder & $\mathrm{m}$ \\
\hline Benthic relief & From video footage, within $2 \mathrm{~m}$ of bait bag & $\begin{array}{l}\text { Categorical } \\
1=<10 \mathrm{~cm} \\
2=10 \mathrm{~cm}-1 \mathrm{~m} \\
3=>1 \mathrm{~m}\end{array}$ \\
\hline Benthic complexity & From video footage, within $2 \mathrm{~m}$ of bait bag & $\begin{array}{l}\text { Categorical } \\
\begin{aligned} 1= & <5 \text { visible holes or crevices } \\
& (>5 \mathrm{~cm} \text { diameter }) \\
2= & 5-10 \text { holes or crevices } \\
3= & >10 \text { holes or crevices }\end{aligned}\end{array}$ \\
\hline Benthic biota density & From video footage, within $2 \mathrm{~m}$ of bait bag & $\begin{array}{l}\text { Categorical } \\
1=<20 \text { individuals } \\
2=20-40 \text { individuals } \\
3=>40 \text { individuals }\end{array}$ \\
\hline Distance to estuary & $\begin{array}{l}\text { ArcGIS v.9.2: distance to nearest } \\
\text { river mouth or estuary opening }\end{array}$ & $\mathrm{km}$ \\
\hline Distance to shore & $\begin{array}{l}\text { ArcGIS v.9.2: distance to nearest part } \\
\text { of the shoreline }\end{array}$ & $\mathrm{km}$ \\
\hline Temperature at bottom & Measured in situ, CTD & ${ }^{\circ} \mathrm{C}$ \\
\hline Salinity at bottom & Measured in situ, CTD & $\%$ \\
\hline Light remaining at bottom & Measured in situ, light logger & $\begin{array}{l}\% \text {, calculated from mean light in bottom } 2 \mathrm{~m} / \\
\text { mean light at surface (lux) }\end{array}$ \\
\hline
\end{tabular}

local benthic community were derived from the fieldof-view of the BRUV. Published quantitative methods for measuring habitat complexity (Luckhurst \& Luckhurst 1978, Friedlander \& Parrish 1998, Wilson et al. 2007) proved unworkable due to both the distortion inherent in the GoPro wide-angle lens and the depth of the reefs (which made manual measurement impossible). Therefore, the estimated distance behind the bait bag ( $2 \mathrm{~m}$ ) was used as the outer limit for assigning 3 complexity descriptors: benthic relief, benthic complexity, and benthic biota density, which were each separated into 3 categories (Table 1). Benthic relief categories were based on vertical heights: $<10 \mathrm{~cm}, 10 \mathrm{~cm}$ to $1 \mathrm{~m}$, and >1 m. Benthic complexity categories were based on the number of visible holes $\sim 5 \mathrm{~cm}$ diameter or greater: $<5,5$ to 10 , and $>10$. Lastly, benthic biota density categories were based on the number of individual benthic organisms visible within $2 \mathrm{~m}$ of the bait bag: $<20,20$ to 40 , and $>40$ (Table 1 ).

\section{Analytical design}

The design tests for differences between the 4 reef bands (fixed: 33, 49, 63, and $80 \mathrm{~m}$ ), and between the 2 locations (fixed: Seaway and Tweed), using both univariate (species richness, total abundance) and multivariate (predatory and scavenging fish assemblage structure) metrics.

Univariate metrics were tested using 2-way (band $\times$ location) general linear models (GLMs) in SPSS v.21. A range of data transformations and model parameters were tested to meet the assumptions of linearity, normality, and homoscedascity; those selected for the final analysis minimised goodness-offit statistics (-2 log likelihood; Akaike's information criterion, AIC and Bayesian's information criterion, BIC). Post hoc tests were conducted on significant terms to determine where the differences lay.

We tested for differences in species richness between latitudinal affiliations and reef bands. Latitudinal affiliations of each species were categorised as tropical, subtropical or temperate based on information in www.fishbase.org (Froese \& Pauly 2013). We acknowledge that latitudinal affiliations of some species in FishBase may be ambiguous or poorly known, therefore conclusions around these categories are drawn with caution.

For each transect, species richness of predatory and scavenging fish within each category was determined, and differences between categories and reef bands were tested using a linear mixed model (LMM) approach. The model tested the fixed factors band and affiliation and the random factor site 
nested within band. As above, the data transformation was selected to minimise goodness-of-fit statistics while satisfying the assumptions of the test.

Differences in predatory and scavenging fish assemblage structure for the same 2-way (band $\times$ location) design were tested using permutational multivariate analysis of variance (PERMANOVA) (Anderson et al. 2008) within the PRIMER 6 software package (Clarke \& Gorley 2006). Multivariate analyses used the conventional Bray-Curtis similarity, because it ignores conjoint absences in a multi-species matrix (Anderson et al. 2008). Patterns in assemblage structure were visualised using non-metric multidimensional scaling (nMDS), and were very consistent across the range of data transformations. Results of PERMANOVA analyses were similarly consistent across data transformations; those presented are based on untransformed data, which had the lowest stress value in the nMDS. Significant relationships were further explored by pairwise testing, using Monte Carlo randomisation if the number of available permutations was low $(<1000)$. The distribution of fish species across reef bands was also examined to determine what proportion of observed species were confined to only 1 band, or ranged across several. SIMPER analysis was used to determine which individual taxa had the greatest influence on the derived patterns.

The influence of putative environmental drivers, both singly and in combination, on derived assemblage pattern was examined using the BIOENV analysis in PRIMER (Clarke \& Gorley 2006), which compares the matrix of biological similarity with matrices derived from different combinations of abiotic variables. The abiotic variables were cross-correlated and, where variable pairs were highly autocorrelated (Spearman's $\rho>0.9$ ), the variable with the lower individual BIOENV correlation was removed to avoid overweighting in the multi-factor BIOENV models.

\section{RESULTS}

\section{Overview}

Between 11 June and 25 August 2013, 32 successful 30 min BRUV deployments were conducted on the 4 bands of rocky reef at 2 locations across the inner continental shelf, with the exception of the deepest reef band where only 1 location was available. Five replicate deployments were sampled at each reef band $\times$ location, except in 3 instances where only 4 landed on reef substrate. The dataset comprised 1917 individuals (based on MaxN) from 101 taxa, including 97 bony fish, 2 sharks and 2 rays (see Table S1 in the Supplement at www.int-res.com/ articles/suppl/m532p185_supp.pdf).

The most abundant species (444 ind.) was the Indian scad Decapterus russelli, although this species was not widespread (5 deployments). The Australian mado Atypichthys strigatus was arguably the most prevalent, being both widespread (25 deployments) and found in high abundance (391 ind.). The snapper Pagrus auratus was the most widely occurring (30 deployments), though present in comparatively low abundances (58 ind.) (Table S1).

In total, 38 fish families were represented; Kyphosidae were the most abundant (604 ind.), closely followed by Carangidae (588). Fewer than 87 individuals were observed from all other families. Sparidae was the most ubiquitous family, appearing in all but 1 deployment, though in relatively low abundance (86 ind.) (Table S1).

\section{Species richness and abundance}

Species richness declined from inshore to offshore reef bands (Table 2, Fig. 2a), and this was consistent for the 2 locations. Species richness at adjacent reef bands ( 33 and $49 \mathrm{~m}, 49$ and $63 \mathrm{~m}, 63$ and $80 \mathrm{~m}$ ) was not significantly different ( $p>0.05)$, but was different for bands more widely separated, supporting the roughly linear decline from inshore to offshore (Fig. 2a).

Table 2. Two-way (band $\times$ location) general linear model (GLM) analyses for species richness and total abundance of predatory and scavenging fishes on continental shelf reefs. Data were $\log _{10}(x+1)$ transformed to meet the assumptions of the test. Significant differences $(p<0.05)$ are given in bold

\begin{tabular}{lcccc} 
Fixed effects & $\begin{array}{c}\text { Numerator } \\
\text { df }\end{array}$ & $\begin{array}{c}\text { Denominator } \\
\text { df }\end{array}$ & $F$ & $p$ \\
\hline $\begin{array}{l}\text { Species richness } \\
\text { Band }\end{array}$ & 3 & 25 & 3.789 & $\mathbf{0 . 0 2 3}$ \\
33 vs. $49 \mathrm{~m}$ & & & & 0.679 \\
33 vs $63 \mathrm{~m}$ & & & & 0.065 \\
33 vs $80 \mathrm{~m}$ & & & & $\mathbf{0 . 0 0 6}$ \\
49 vs $63 \mathrm{~m}$ & & & & 0.144 \\
49 vs $80 \mathrm{~m}$ & & 25 & 0.297 & 0.591 \\
63 vs $80 \mathrm{~m}$ & 1 & 25 & 0.359 & 0.702 \\
Location & 2 & & & \\
Band $\times$ Location & 2 & 25 & 0.721 & 0.549 \\
Total abundance & & 25 & 2.216 & 0.149 \\
Band & 3 & 25 & 2.054 & 0.149 \\
Location & 1 & & & \\
Band $\times$ Location & 2 & & &
\end{tabular}




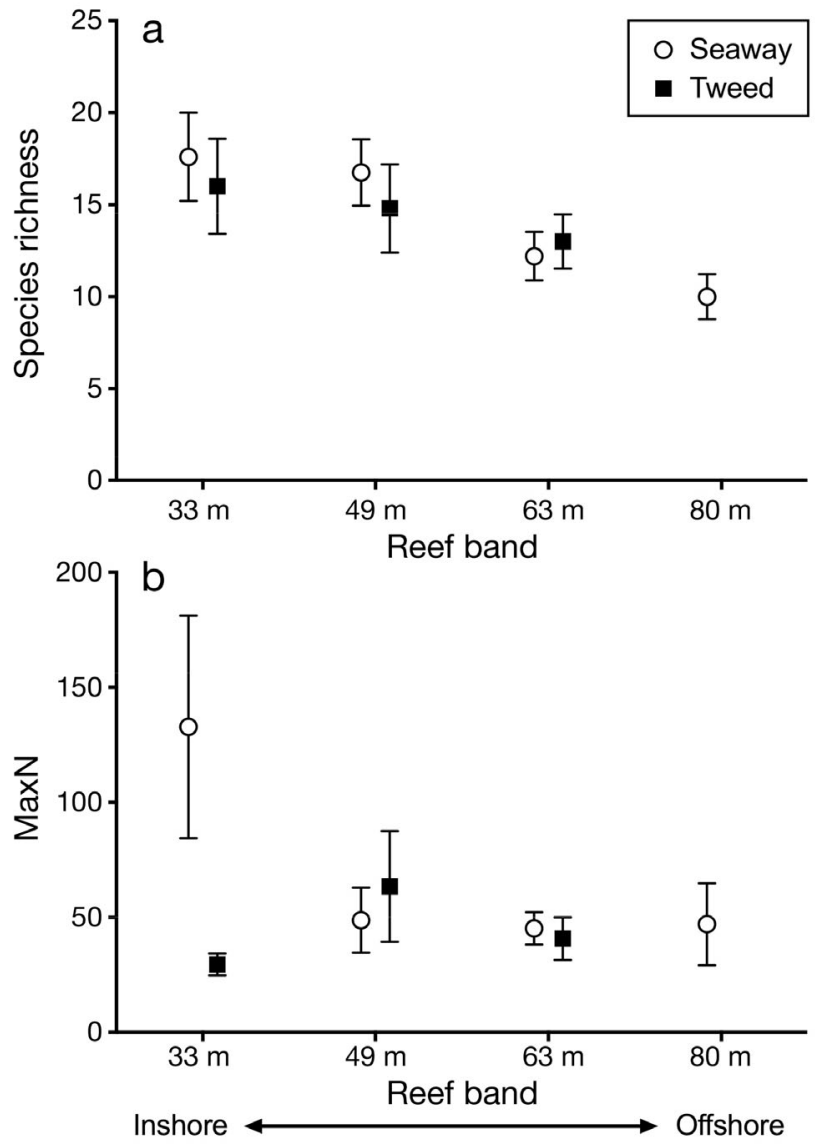

Fig. 2. Mean $( \pm \mathrm{SE})$ (a) species richness and (b) total abundance (MaxN) from baited remote underwater video (BRUV) sampling of predatory and scavenging fishes on continental shelf reefs

In contrast, total abundance of predatory and scavenging fishes was not different between reef bands or locations (Table 2, Fig. 2b). In spite of the apparent difference between locations inshore $(33 \mathrm{~m}$ reef band), when transformed to meet the assumptions of the test there was no statistical difference. This was confirmed by pairwise testing ( $p>0.05$ for all band $x$ location combinations), and was consistent across different valid transformations.

\section{Latitudinal affiliations}

Analysis of the latitudinal affiliations associated with species richness within each band of reef revealed no significant interaction $(p=0.661)$ in the reef band $\times$ affiliation term (Table 3, Fig. 3), indicating that there was no change in latitudinal affiliation across the shelf. As suggested by Fig. 3, there were differences within the affiliation term $(\mathrm{p}<0.001)$, with pairwise analysis revealing that subtropical spe-
Table 3. Linear mixed model (LMM) analyses for species richness by latitudinal affiliation (tropical, subtropical, temperate) and reef band $(33,49,63$, and $80 \mathrm{~m})$ of predatory and scavenging fish species on continental shelf reefs. Species richness was $\log _{10}(x+1)$ transformed to meet the assumptions of the test. Significant differences $(p<0.05)$ are given in bold

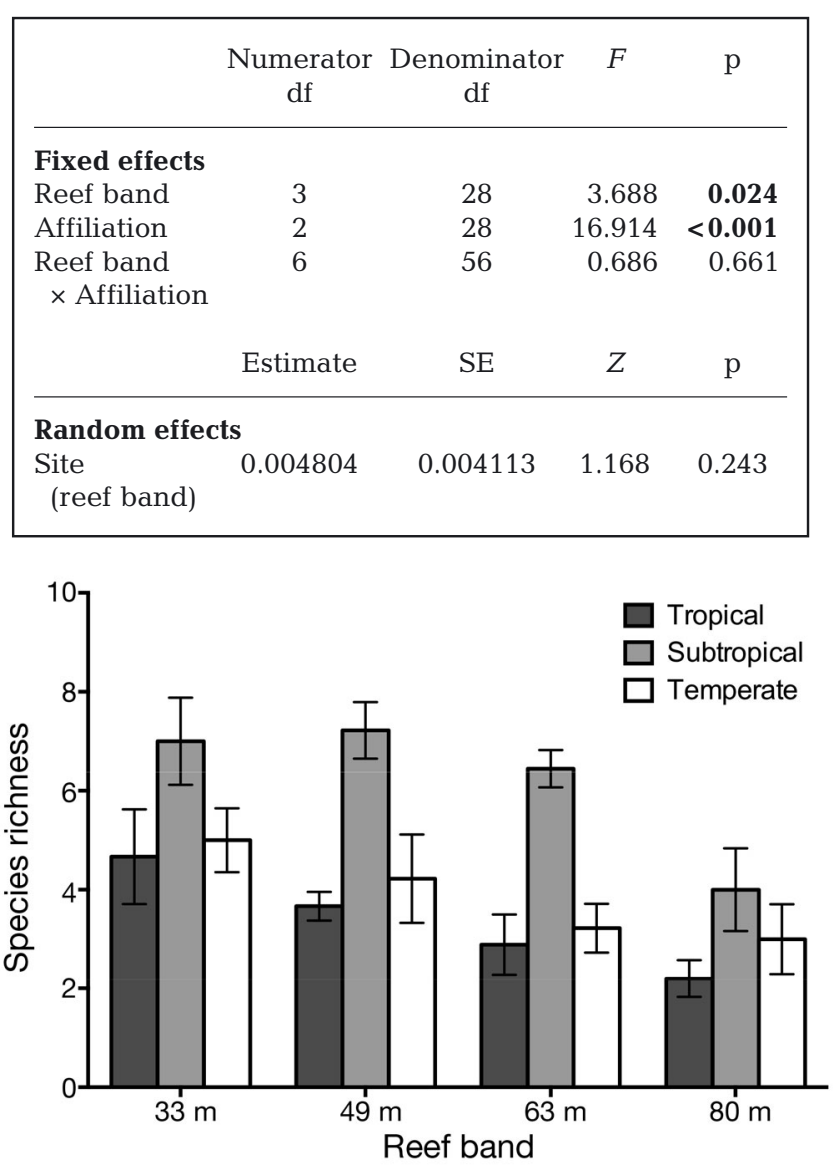

Fig. 3. Latitudinal affiliation of predator and scavenger fishes at each reef band as mean $( \pm \mathrm{SE})$ species richness in each category

cies richness was significantly different $(p<0.001)$ from both temperate and tropical species richness, which were not different from one another $(p=0.294)$. There were significant differences between reef bands, consistent with the previous analysis.

\section{Assemblage structure}

There were clear patterns in predatory and scavenging fish assemblage structure (Fig. 4), confirmed by the significant PERMANOVA interaction term (Table 4). Pairwise test results showed that the assemblage at the furthest offshore sites ( $80 \mathrm{~m}$ band) was clearly distinct. Of the shallower 3 bands, assemblage structure at adjacent sites was not significantly 


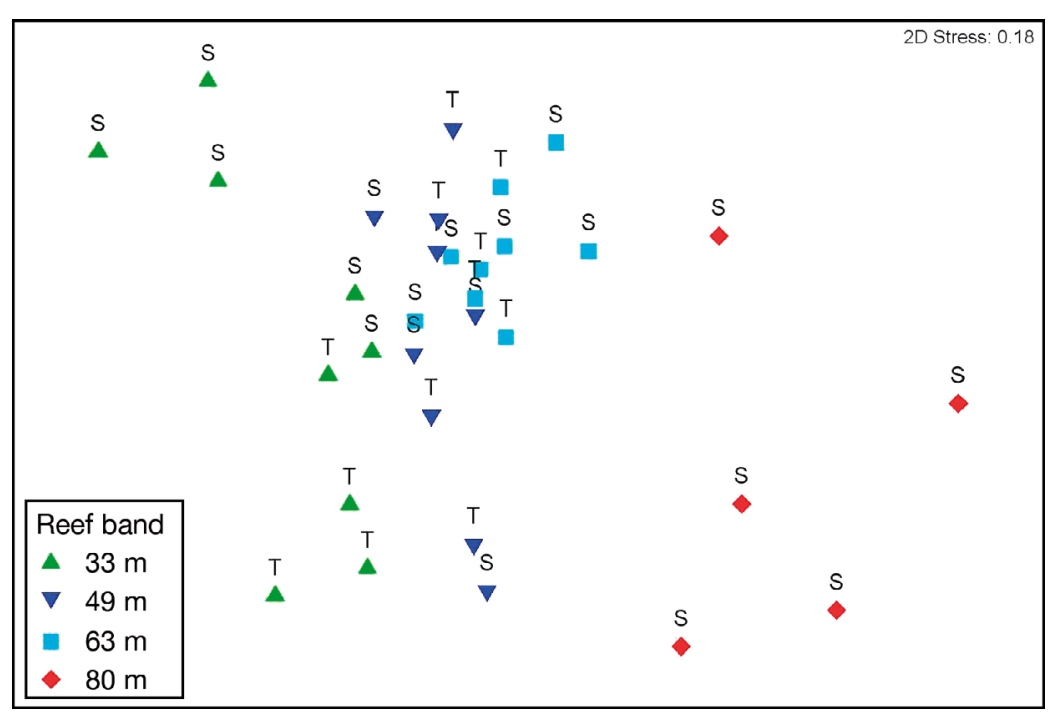

Fig. 4. Non-metric multidimensional scaling (nMDS) of predator and scavenger fish assemblage structure from baited remote underwater video (BRUV) sampling on continental shelf reefs. Symbols correspond to the sites illustrated in Fig. 1; S: Southport Seaway; T: Tweed River. Results are based on Bray-Curtis similarity from untransformed data; other transformations showed very similar patterns, but with higher stress levels

Table 4. Two-way (band $\times$ location) PERMANOVA for predatory and scavenging fish assemblage structure on continental shelf reefs. Based on Bray-Curtis similarity matrix from untransformed data. p-values derived by Monte-Carlo randomisation for pairwise tests because the number of unique permutations was low. Significant differences $(p<0.05)$ are given in bold

\begin{tabular}{|c|c|c|c|c|c|}
\hline & $\begin{array}{c}\text { Numerator } \\
\text { df }\end{array}$ & $\begin{array}{c}\text { Denominator } \\
\text { df }\end{array}$ & Pseudo-F & $\mathrm{p}$ & $\begin{array}{c}\text { Unique } \\
\text { permutations }\end{array}$ \\
\hline \multicolumn{6}{|l|}{ Fixed effects } \\
\hline Band & 3 & 25 & 3.265 & $<0.001$ & 9859 \\
\hline Location & 1 & 25 & 1.583 & 0.092 & 9882 \\
\hline Band $\times$ Location & 2 & 25 & 1.850 & 0.012 & 9886 \\
\hline Pairwise & & & $t$ & $\mathrm{p}$ & $\begin{array}{c}\text { Unique } \\
\text { permutations }\end{array}$ \\
\hline \multicolumn{6}{|l|}{ Seaway } \\
\hline 33 vs. $49 \mathrm{~m}$ & & & 1.565 & 0.068 & 126 \\
\hline 33 vs. $63 \mathrm{~m}$ & & & 1.754 & 0.030 & 126 \\
\hline 33 vs. $80 \mathrm{~m}$ & & & 1.831 & 0.012 & 126 \\
\hline 49 vs. $63 \mathrm{~m}$ & & & 1.291 & 0.156 & 126 \\
\hline 49 vs. $80 \mathrm{~m}$ & & & 1.550 & 0.040 & 126 \\
\hline 63 vs. $80 \mathrm{~m}$ & & & 1.702 & 0.018 & 126 \\
\hline \multicolumn{6}{|l|}{ Tweed } \\
\hline 33 vs. $49 \mathrm{~m}$ & & & 1.455 & 0.085 & 126 \\
\hline 33 vs. $63 \mathrm{~m}$ & & & 2.222 & 0.008 & 35 \\
\hline 49 vs. $63 \mathrm{~m}$ & & & 1.253 & 0.195 & 126 \\
\hline \multicolumn{6}{|c|}{ Seaway vs. Tweed } \\
\hline $33 \mathrm{~m}$ & & & 1.894 & 0.019 & 126 \\
\hline $49 \mathrm{~m}$ & & & 1.056 & 0.354 & 126 \\
\hline $63 \mathrm{~m}$ & & & 1.004 & 0.403 & 126 \\
\hline
\end{tabular}

different $(\mathrm{p}>0.05)$. However, the 2 more spatially separated sites (33 and $63 \mathrm{~m})$ did display significant differences $(p<0.05)$, reinforcing the picture of progressive change in the predatory and scavenging fish fauna from inshore to offshore. Assemblage structure at the most inshore band (33 m) was different between the Tweed and Seaway locations $(\mathrm{p}=$ 0.019 ), but this was not the case at the 49 or $63 \mathrm{~m}$ bands.

At the most inshore reef band, $45 \%$ of fish species were observed in no other reef band (Table 5a). This proportion fell to $15 \%$ at the $63 \mathrm{~m}$ band, but rose again to $41 \%$ at the $80 \mathrm{~m}$ band (only sampled offshore from the Seaway), highlighting the distinct fish assemblage in this deepest, furthest offshore reef band, as shown by the nMDS and pairwise results. Overall, more than half the observed fish fauna (55 of 101 species; Table 5b) occurred at only 1 depth band, with only 6 species observed at all 4 bands. A total of 9 species were observed within both the shallowest and deepest reef bands (Table S1).

SIMPER analyses indicated that 3 species (Decapterus russelli, Atypichthys strigatus, and Seriola dumerili) were the highest contributors to dissimilarity between reef bands, and to similarity within the bands. D. russelli was the single most abundant species in the study (Table S1), but was only observed within the $33 \mathrm{~m}$ band. It therefore represented a large proportion of the difference between the $33 \mathrm{~m}$ and all other reef bands (SIMPER: 33 vs. $49 \mathrm{~m}=24 \% ; 63 \mathrm{~m}=28 \% ; 80 \mathrm{~m}=$ $40 \%$ ). This species also accounted for $30 \%$ of the similarity within $33 \mathrm{~m}$ reef bands. At the other end of the depth spectrum, $S$. dumerili was the 3 rd most abundant fish species, but occurred only in the $80 \mathrm{~m}$ reef band, thus accounting for the greatest contribution to assemblage dissimilarity (17\%) between the 49 and $80 \mathrm{~m}$ reef bands, and $24 \%$ of similarity within the $80 \mathrm{~m}$ band. A. strigatus (the 2nd most abun- 
Table 5. Fish species distributions between reef bands, as (a) proportion of all fish species occurring at a reef band that occur only at that reef band, and (b) number of fish species by the number of reef bands in which they occur. A total of 9 baited remote underwater video (BRUV) samples were taken at each reef band except for the $80 \mathrm{~m}$ reef band where $\mathrm{n}=5$, since this depth was not sampled at the Tweed location

\begin{tabular}{|lccc|}
\hline $\begin{array}{l}\text { (a) } \\
\text { Reef } \\
\text { band }\end{array}$ & $\begin{array}{c}\text { Total no. } \\
\text { of fish species } \\
\text { occurring }\end{array}$ & $\begin{array}{c}\text { No. of fish } \\
\text { species occurring } \\
\text { only in this band }\end{array}$ & $\begin{array}{c}\text { Proportion } \\
\text { occurring only in } \\
\text { this band (\%) }\end{array}$ \\
\hline $33 \mathrm{~m}$ & 55 & 25 & 45 \\
$49 \mathrm{~m}$ & 55 & 14 & 25 \\
$63 \mathrm{~m}$ & 39 & 6 & 15 \\
$80 \mathrm{~m}$ & 27 & 11 & \\
& & & \\
(b) & & & \\
No. of & No. of & & \\
bands & fish species & & \\
\hline 1 & 56 & & \\
2 & 21 & & \\
3 & 18 & & \\
4 & 6 & & \\
\hline
\end{tabular}

vdant fish species; Table S1) occurred across all 4 reef bands, but at different densities. It was responsible for $25 \%$ of assemblage dissimilarity between the 49 and $63 \mathrm{~m}$ bands, and $20 \%$ of dissimilarity between the 63 and $80 \mathrm{~m}$ bands. A. strigatus accounted for $34 \%$ of similarity within the $49 \mathrm{~m}$ reef band and $58 \%$ of similarity within the $63 \mathrm{~m}$ reef band.

\section{Drivers of assemblage structure}

BIOENV analyses of individual drivers of predatory and scavenging fish assemblage showed that depth, distance to shore, and distance to estuary were the most important factors, all with similar correlation values (Table 6). Not surprisingly, these were strongly autocorrelated, and thus only depth was used in the subsequent combined models. Salinity, benthic relief, and benthic complexity all had a significant influence $(p \leq 0.004)$, although correlation values were low (approximately 0.2). Perhaps surprisingly, light, temperature, and benthic density had no detectable influence ( $p>0.05$; Table 6$)$. Separate analyses of light intensity versus depth from the CTD to which it was attached showed the expected strong negative exponential relationship $\left(r^{2}=0.747\right)$. However, light intensity varied markedly at small spatial and temporal scales, indicating that 'snapshot' readings may be of little value, and that long-term mean values would be required to assess the direct rela-
Table 6. BIOENV analysis: Spearman's correlations of individual drivers and best combined models with observed predator and scavenger fish assemblage structure. Based on ranked Euclidean distance similarity for abiotic data, and Bray-Curtis similarity from untransformed data on fish assemblage structure. Values in bold denote significant $(\mathrm{p}<$ 0.05 ) correlations. $\mathrm{n}=32$, except for 'light remaining' values, which were not available for all deployments; this value is based on a reduced set of 25

\begin{tabular}{|lcr|}
\hline & $\rho$ & $\mathrm{p}$ \\
\hline Individual drivers & & \\
Depth & 0.396 & $\mathbf{< 0 . 0 0 1}$ \\
Distance to estuary & 0.366 & $\mathbf{< 0 . 0 0 1}$ \\
Distance to shore & 0.358 & $\mathbf{< 0 . 0 0 1}$ \\
Salinity & 0.218 & $\mathbf{< 0 . 0 0 1}$ \\
Benthic relief & 0.210 & $\mathbf{0 . 0 0 2}$ \\
Benthic complexity & 0.195 & $\mathbf{0 . 0 0 4}$ \\
Light remaining & 0.079 & 0.143 \\
Bottom temp & 0.075 & 0.136 \\
Benthic biota density & 0.036 & 0.224 \\
& & \\
Best models & & \\
Depth & 0.396 & $\mathbf{2 0 . 0 0 1}$ \\
& & in every case \\
Depth, salinity & 0.384 & \\
Depth, relief, salinity & 0.347 & \\
Depth, complexity, salinity & 0.342 & \\
Depth, relief, bottom temperature, & 0.330 & \\
salinity & & \\
\hline
\end{tabular}

tionship between light and assemblage structure. It also suggests that depth is a suitable proxy for light intensity in short term studies such as this.

The BIOENV model that best explained the observed patterns in predatory and scavenging fishes contained depth alone $(\rho=0.396, p<0.001)$. Adding drivers to the model, while still displaying relatively high correlations, only resulted in a weaker relationship with assemblage structure (Table 6). This was also the case if either of the terms autocorrelated with depth (distance to estuary and distance to shore) was substituted for depth in the analysis (data not shown).

\section{DISCUSSION}

\section{Summary}

This study revealed the existence of a very clear and consistent cross-shelf gradient in species richness of scavenging and predatory fishes on mesophotic rocky reefs that declines approximately linearly over 4 reef bands within a depth range of 30 to $82 \mathrm{~m}$. Perhaps surprisingly, this was not matched by a gradient in overall abundance, which was not signif- 
icantly different between depths or locations, in contrast to patterns reported elsewhere (see Kahng et al. 2014 for review).

Multivariate analyses of fish assemblage structure revealed a clear cross-shelf pattern. Assemblages at adjacent reef bands were generally not significantly different, but were different from those further away. The scavenging and predatory fish assemblage at the $80 \mathrm{~m}$ band was different from all others, but the latitudinal analysis showed, perhaps surprisingly, that this did not represent a tropical dominated assemblage recruiting from reefs further north, as would be expected if the offshore reefs were influenced by the southward flowing EAC. The fish assemblage was dominated by subtropical fish species at all reef bands. While the 33, 49, and $63 \mathrm{~m}$ reef bands were more closely related to one another, each contained a subset of species (ranging from 15 to $45 \%$ ) that were not observed at other bands.

Depth was the most important individual driver for patterns in assemblage structure, and on its own was better than any combination of drivers. However, distance to shore and to the nearest estuary were nearly as important, and salinity, benthic relief, and complexity were also significantly related to observed assemblage structure.

\section{Relationship with other fish studies}

Studies on reef fish fauna at the SIMP, on the eastern Australian coast about $260 \mathrm{~km}$ south of the present study, reveal contrasting trends when comparing distance from shore and depth gradients. Malcolm et al. (2010a) found that species richness on shallow $(<25 \mathrm{~m})$ reefs increased with distance offshore, and that this was largely a result of the addition of tropical species. However, species richness decreased with depth down to $65 \mathrm{~m}$ (Malcolm et al. 2011b), as was the case in this study. Further afield, fish species richness at subtropical (ca. 28.5 ${ }^{\circ} \mathrm{N}$ ) mesophotic reefs also declined with depth in the Gulf of Aqaba (Brokovich et al. 2008), as did the density of specific trophic levels (e.g. grazing fishes) (Brokovich et al. 2010).

In tropical coral reef locations, there is a distinct transition between euphotic and mesophotic fish communities, with a general pattern of increasing fish species richness to a maximum at about 25 to $30 \mathrm{~m}$, then decreasing monotonically to the lower limit of the survey, typically 50 to $65 \mathrm{~m}$ (e.g. Garcia-Sais 2010, Kahng et al. 2010). At Isla Desecheo in the Carribean, Garcia-Sais (2010) defined distinct differences in fish assemblages between euphotic (15 to $25 \mathrm{~m}$ ) and mesophotic (30 to $50 \mathrm{~m}$ ) depths, as well as distinct differences within the mesophotic zone, with the deepest $(50 \mathrm{~m})$ being different from all other depths. Detailed mesophotic fish assemblage surveys are rare in the literature, but a similar picture is apparent from locations in the southwest Atlantic (Pereira-Filho et al. 2011), the Gulf of Mexico (Dennis \& Bright 1988) and western Australia (Fitzpatrick et al. 2012). Our results are consistent with these trends in both tropical and subtropical regions in that fish assemblage is clearly different between upper- and mid-mesophotic depths. Comparable studies in temperate waters typically sample a far greater depth range, in that they sample the mesophotic zone as the upper extent of surveys into aphotic depths. Nonetheless, fish species richness and assemblage structure are also strongly related to depth, both in the mesophotic (Williams \& Bax 2001) and euphotic depths (Hyndes et al. 1999).

High levels of apparent depth-endemism were observed in this study as over half of the species occurred in only 1 reef band, similar to observations elsewhere in the Pacific (Pyle et al. 2008, Kane et al. 2014), although it is not possible to separate the depth effect from distance offshore in this study. Of the 101 species encountered, only 9 appeared in both 33 and $80 \mathrm{~m}$ bands, and only 6 occurred across all depth bands. In contrast, 56 species were apparent depth specialists. Therefore, the capacity of the deep reefs to act as refuges and sources of recruitment for shallower reefs may be limited to a relatively small pool of species, although investigations over longer time spans would be required to determine this. That said, the deep reef refugia hypothesis relates to the re-supply of euphotic reefs (Bongaerts et al. 2010), which were not examined in this study. Nevertheless, our findings add weight to the importance of mesophotic reefs in maintaining biodiversity through harbouring apparently depth-specialist species.

The sites on the reef bands we surveyed constitute spatially isolated reefs emerging a few metres above the flat sandy sediments of the continental shelf, which fall only $50 \mathrm{~m}$ over a distance of more than $30 \mathrm{~km}$. Given that the $80 \mathrm{~m}$ reef band is about $16 \mathrm{~km}$ from the nearest $63 \mathrm{~m}$ reef, it is not surprising that the fish assemblage here is distinct from all others, but nonetheless interesting that latitudinal affiliations are not different. Furthermore, trends in species richness across the depth range of the continental shelf conform to those from the bulk of studies, most of which examined different depths on a continuous rocky or coral reef slope. This has important implications for scales of connectivity in mesophotic reefs (Slattery et al. 2011) and for reserve design. 


\section{Relationship with benthic assemblages}

Published trends in macrobenthic species richness, abundance, and assemblage structure of mesophotic reefs vary widely, but do not necessarily correspond to observed patterns in fish assemblages. Richmond \& Stevens (2014) documented macrobenthic assemblage structure at the same reefs as the current study (excluding the $80 \mathrm{~m}$ sites) as part of a wider appraisal of benthic biodiversity in the region. Unlike the current study, macrobenthic assemblages were distinctly different between the Seaway and Tweed locations for the inner 2 reef bands, but not separated at the $63 \mathrm{~m}$ band, which was different from the shallower assemblages. There were also distinct gradients in both species richness and total abundance of macrobenthic taxa, which both increased with depth and distance offshore (Richmond \& Stevens 2014). That is, the observed gradients were the opposite of that found for predatory and scavenging fish species richness in this study, indicating that the fish and benthos are not closely coupled in this setting. In addition, assemblages in the $63 \mathrm{~m}$ reef band were characterised by the presence of tropical taxa not found at the shallower, more inshore reefs. This is consistent with other eastern Australian benthic studies (e.g. Harrison \& Smith 2012), and is attributed to the influence of the south-flowing EAC bringing invertebrate larval forms from tropical waters, which then settle and colonise the offshore reefs, whereas inshore reefs are subjected to a northward flowing counter current. However, it is apparent that these influences do not appear to operate in the same way for scavenging and predatory fish in this situation, although the influence of the EAC is cited as a driver for patterns in fish assemblage structure in the Solitary Islands (Malcolm et al. 2010b) where there is moderately good correlation between fish and dominant benthic assemblages (Malcolm et al. 2011b). Richmond \& Stevens (2014) speculated that some near-shore reefs maybe overfished, leading to a trophic cascade, but further work is required to test this assertion.

\section{Possible drivers of observed fish assemblage patterns}

The role of depth as a key driver for fish assemblage patterns fits with findings elsewhere (Malcolm et al. $2010 \mathrm{~b}, 2011 \mathrm{~b})$, though it is rarely the sole driver; distance from shore, habitat structure, and species diversity also show positive relationships with fish assemblage structure (Luckhurst \& Luckhurst 1978, GarcíaCharton \& Pérez-Ruzafa 1998, Gomelyuk 2009, Mc-
Clain \& Barry 2010). We found that depth alone is the best indicator of assemblage structure, but in part, this may be because the arrangement of reefs relative to the coast in the current study was linear. Shallow reefs only occur near shore, and deep reefs only occur offshore in the study area. Thus, it is not possible to separate the influence of depth and distance offshore due to simultaneous changes in each. In addition, our study reports on the fish fauna of reefs separated by $10 \mathrm{~s}$ of $\mathrm{kms}$ of sand flats whereas many others report on different depths within the same reefs (e.g. Brokovich et al. 2008, Bejarano et al. 2014).

Given the long established relationship between light penetration and depth (Gordon \& McCluney 1975), it should be noted that the depth-based relationship identified here cannot be disentangled from the effect of decreasing light availability. That said, high spatio-temporal variation in water clarity means that depth is generally a more practical proxy for long-term light intensity averages (see Armstrong et al. 2006, Smith et al. 2010, and Amado-Filho et al. 2012 for examples). However, light alone is unlikely to be limiting at most of the depths studied, given that the kelp Ecklonia radiata is found at high densities at depths of ca. $70 \mathrm{~m}$ offshore from Moreton Island, less than $100 \mathrm{~km}$ north of the study area (Marin 2013, Richmond \& Stevens 2014). In other mesophotic ecosystems throughout the world, reported shifts from herbivory to carnivory (especially planktivory; Kahng et al. 2010) with depth, even where edible macroalgae is abundant (Garcia-Sais 2010), suggest that other factors are at play. In the local context, these could include localised shelf-break upwellings (Baird et al. 2006, Dela-Cruz et al. 2008, Marin 2013) or fishing pressure (Richmond \& Stevens 2014).

\section{Future research}

Much work remains to be done to establish the wider role of mesophotic reefs in continental shelf ecology. In the local context, studies to examine the along-shelf distribution patterns of nektonic taxa are underway. Future studies in the region would benefit greatly from more detailed bathymetric data (e.g. from swath or multibeam acoustic surveys). Such information is necessary to design studies to examine the more pressing questions raised in this studyspecifically, to understand scales of connectivity in fish and invertebrate biota between isolated reef outcrops and their relationship with the fauna of interreef soft substrates - information that is critical for future conservation initiatives. 
Acknowledgements. We thank colleagues in the Griffith School of Environment and the Australian Rivers Institute for productive discussions and advice during the design phase, particularly Michael Arthur. We are grateful to Lorry Hughes from the Griffith Centre for Coastal Management for the use of the CTD. The study was funded in part by the Australian Rivers Institute.

\section{LITERATURE CITED}

Allen GR (2009) Field guide to marine fishes of tropical Australia and south-east Asia. Western Australian Museum, Welshpool

Allen GR, Steene R, Humann P, Deloach N (2003) Reef fish identification: tropical Pacific. New World Publications, Jacksonville, FL

Amado-Filho GM, Pereira-Filho GH, Bahia RG, Abrantes DP, Veras PC, Matheus Z (2012) Occurrence and distribution of rhodolith beds on the Fernando de Noronha Archipelago of Brazil. Aquat Bot 101:41-45

Anderson M, Gorley RN, Clarke KR (2008) PERMANOVA+ for PRIMER: guide to software and statistical methods. PRIMER-E, Plymouth

Armstrong RA, Singh H, Torres J, Nemeth RS and others (2006) Characterizing the deep insular shelf coral reef habitat of the Hind Bank marine conservation district (US Virgin Islands) using the Seabed autonomous underwater vehicle. Cont Shelf Res 26:194-205

Baird ME, Timko PG, Suthers IM, Middleton JH (2006) Coupled physical-biological modelling study of the East Australian Current with idealised wind forcing: Part II. Biological dynamical analysis. J Mar Syst 59: 271-291

> Bejarano I, Appeldoorn R, Nemeth M (2014) Fishes associated with mesophotic coral ecosystems in La Parguera, Puerto Rico. Coral Reefs 33:313-328

> Bernard ATF, Götz A (2012) Bait increases the precision in count data from remote underwater video for most subtidal reef fish in the warm-temperate Agulhas bioregion. Mar Ecol Prog Ser 471:235-252

Bongaerts P, Ridgway T, Sampayo EM, Hoegh-Guldberg O (2010) Assessing the 'deep reef refugia' hypothesis: focus on Caribbean reefs. Coral Reefs 29:309-327

Bridge TCL, Fabricius KE, Bongaerts P, Wallace CC, Muir PR, Done TJ, Webster JM (2012) Diversity of Scleractinia and Octocorallia in the mesophotic zone of the Great Barrier Reef, Australia. Coral Reefs 31:179-189

Brokovich E, Einbinder S, Shashar N, Kiflawi M, Kark S (2008) Descending to the twilight-zone: changes in coral reef fish assemblages along a depth gradient down to 65 m. Mar Ecol Prog Ser 371:253-262

> Brokovich E, Ayalon I, Einbinder S, Segev N and others (2010) Grazing pressure on coral reefs decreases across a wide depth gradient in the Gulf of Aqaba, Red Sea. Mar Ecol Prog Ser 399:69-80

Cappo M, Speare P, De'ath G (2004) Comparison of baited remote underwater video stations (BRUVS) and prawn (shrimp) trawls for assessments of fish biodiversity in inter-reefal areas of the Great Barrier Reef Marine Park. J Exp Mar Biol Ecol 302:123-152

Clarke KR, Gorley RN (2006) PRIMER v6: user manual/tutorial. PRIMER-E, Plymouth

> Colton MA, Swearer SE (2010) A comparison of two survey methods: differences between underwater visual census and baited remote underwater video. Mar Ecol Prog Ser 400:19-36

Davie P, Cranitch G, Wright J, Cowell B (2011) Wild guide to Moreton Bay and adjacent coasts. Queensland Museum, South Brisbane

Dela-Cruz J, Middleton J, Suthers I (2008) The influence of upwelling, coastal currents and water temperature on the distribution of the red tide dinoflagellate, Noctiluca scintillans, along the east coast of Australia. Hydrobiologia 598:59-75

Dennis GD, Bright TJ (1988) Reef fish assemblages on hard banks in the northwestern Gulf of Mexico. Bull Mar Sci 43:280-307

> Duffy JE (2002) Biodiversity and ecosystem function: the consumer connection. Oikos 99:201-219

Edgar GJ, Davey A, Kelly G, Mawbey RB, Parsons K (2010) Biogeographical and ecological context for managing threats to coral and rocky reef communities in the Lord Howe Island Marine Park, south-western Pacific. Aquat Conserv 20:378-396

Fitzpatrick BM, Harvey ES, Heyward AJ, Twiggs EJ, Colquhoun J (2012) Habitat specialization in tropical continental shelf demersal fish assemblages. PLoS ONE $7: \mathrm{e} 39634$

Friedlander AM, Parrish JD (1998) Habitat characteristics affecting fish assemblages on a Hawaiian coral reef. J Exp Mar Biol Ecol 224:1-30

Froese R, Pauly D (eds) (2013) FishBase. www.fishbase.org (accessed 18 Apr 2013)

García-Charton JA, Prez-Ruzafa A (1998) Correlation between habitat structure and a rocky reef fish assemblage in the southwest Mediterranean. Mar Ecol 19:111-128

> Garcia-Sais JR (2010) Reef habitats and associated sessilebenthic and fish assemblages across a euphotic-mesophotic depth gradient in Isla Desecheo, Puerto Rico. Coral Reefs 29:277-288

> Gomelyuk VE (2009) Fish assemblages composition and structure in three shallow habitats in north Australian tropical bay, Garig Gunak Barlu National Park, Northern Territory, Australia. J Mar Biol Assoc UK 89:449-460

> Gordon HR, McCluney W (1975) Estimation of the depth of sunlight penetration in the sea for remote sensing. Appl Opt 14:413-416

Halpern BS, Longo C, Hardy D, McLeod KL and others (2012) An index to assess the health and benefits of the global ocean. Nature 488:615-620

Harrison MA, Smith SDA (2012) Cross-shelf variation in the structure of molluscan assemblages on shallow, rocky reefs in subtropical, eastern Australia. Mar Biodivers 42: 203-216

> Harvey ES, Cappo M, Butler JJ, Hall N, Kendrick GA (2007) Bait attraction affects the performance of remote underwater video stations in assessment of demersal fish community structure. Mar Ecol Prog Ser 350:245-254

> Hixon MA, Carr MH (1997) Synergistic predation, density dependence, and population regulation in marine fish. Science 277:946-949

> Hoegh-Guldberg O (1999) Climate change, coral bleaching and the future of the world's coral reefs. Mar Freshw Res 50:839-866

> Hughes TP, Baird AH, Bellwood DR, Card M and others (2003) Climate change, human impacts, and the resilience of coral reefs. Science 301:929-933

Hyndes GA, Platell ME, Potter IC, Lenanton RCJ (1999) Does the composition of the demersal fish assemblages 
in temperate coastal waters change with depth and undergo consistent seasonal changes? Mar Biol 134: 335-352

Kahng SE, Garcia-Sais JR, Spalding HL, Brokovich E and others (2010) Community ecology of mesophotic coral reef ecosystems. Coral Reefs 29:255-275

Kahng SE, Copus JM, Wagner D (2014) Recent advances in the ecology of mesophotic coral ecosystems (MCEs). Curr Opin Environ Sustain 7:72-81

Kane C, Kosaki RK, Wagner D (2014) High levels of mesophotic reef fish endemism in the northwestern Hawaiian Islands. Bull Mar Sci 90:693-703

Keane JP, Neira FJ (2008) Larval fish assemblages along the south-eastern Australian shelf: linking mesoscale nondepth-discriminate structure and water masses. Fish Oceanogr 17:263-280

Kuiter RH (1996) Guide to sea fishes of Australia. New Holland, Frenchs Forest

Lesser MP, Slattery M, Leichter JJ (2009) Ecology of mesophotic coral reefs. J Exp Mar Biol Ecol 375:1-8

Luckhurst BE, Luckhurst K (1978) Analysis of the influence of substrate variables on coral reef fish communities. Mar Biol 49:317-323

Malcolm HA, Gladstone W, Lindfield S, Wraith J, Lynch TP (2007) Spatial and temporal variation in reef fish assemblages of marine parks in New South Wales, Australia baited video observations. Mar Ecol Prog Ser 350: 277-290

Malcolm HA, Jordan A, Smith SDA (2010a) Biogeographical and cross-shelf patterns of reef fish assemblages in a transition zone. Mar Biodivers 40:181-193

Malcolm HA, Smith SDA, Jordan A (2010b) Using patterns of reef fish assemblages to refine a habitat classification system for marine parks in NSW, Australia. Aquat Conserv Mar Freshw Ecosyst 20:83-92

Malcolm HA, Davies PL, Jordan A, Smith SDA (2011a) Variation in sea temperature and the East Australian Current in the Solitary Islands region between 2001-2008. DeepSea Res II 58:616-627

Malcolm HA, Jordan A, Smith SDA (2011b) Testing a depthbased habitat classification system against reef fish assemblage patterns in a subtropical marine park. Aquat Conserv Mar Freshw Ecosyst 21:173-185

Marin M (2013) Modelling the distribution of a vertically structured sub-tropical water column, using local hydrodynamic model outputs. BSc Hons thesis, University of Queensland, Brisbane

> McClain CR, Barry JP (2010) Habitat heterogeneity, disturbance, and productivity work in concert to regulate biodiversity in deep submarine canyons. Ecology 91:964-976

McClanahan TR (1995) Fish predators and scavengers of the

Editorial responsibility: Janet Ley, St. Petersburg, Florida, USA sea urchin Echinometra mathaei in Kenyan coral-reef marine parks. Environ Biol Fishes 43:187-193

- Neira FJ, Keane JP (2008) Ichthyoplankton-based spawning dynamics of blue mackerel (Scomber australasicus) in south-eastern Australia: links to the East Australian Current. Fish Oceanogr 17:281-298

Pereira-Filho GH, Amado-Filho GM, Guimarães SMPB, Moura RL and others (2011) Reef fish and benthic assemblages of the Trindade and Martin Vaz island group, southwestern Atlantic. Braz J Oceanogr 59:201-212

Puglise K, Hinderstein L, Marr J, Dowgiallo M, Martinez F (2009) Mesophotic coral ecosystems research strategy: international workshop to prioritize research and management needs for mesophotic coral ecosystems. Jupiter, FL, 12-15 July 2009. NOAA Tech Memo NOS NCCOS 98, Silver Spring, MD

Pyle RL, Earle JL, Greene BD (2008) Five new species of the damselfish genus Chromis (Perciformes: Labroidei: Pomacentridae) from deep coral reefs in the tropical western Pacific. Zootaxa 1671:3-31

Richmond S, Stevens T (2014) Classifying benthic biotopes on sub-tropical continental shelf reefs: How useful are abiotic surrogates? Estuar Coast Shelf Sci 138:79-89

Riegl B, Piller WE (2003) Possible refugia for reefs in times of environmental stress. Int J Earth Sci 92:520-531

Sala E (1997) Fish predators and scavengers of the sea urchin Paracentrotus lividus in protected areas of the north-west Mediterranean Sea. Mar Biol 129:531-539

Slattery M, Lesser MP, Brazeau D, Stokes MD, Leichter JJ (2011) Connectivity and stability of mesophotic coral reefs. J Exp Mar Biol Ecol 408:32-41

Smith TB, Blondeau J, Nemeth RS, Pittman SJ, Calnan JM, Kadison E, Gass J (2010) Benthic structure and cryptic mortality in a Caribbean mesophotic coral reef bank system, the Hind Bank Marine Conservation District, US Virgin Islands. Coral Reefs 29:289-308

Tenggardjaja KA, Bowen BW, Bernardi G (2014) Vertical and horizontal genetic connectivity in Chromis verater, an endemic damselfish found on shallow and mesophotic reefs in the Hawaiian archipelago and adjacent Johnston Atoll. PLoS ONE 9:e115493

Williams A, Bax NJ (2001) Delineating fish-habitat associations for spatially based management: an example from the south-eastern Australian continental shelf. Mar Freshw Res 52:513-536

Willis TJ, Babcock RC (2000) A baited underwater video system for the determination of relative density of carnivorous reef fish. Mar Freshw Res 51:755-763

Wilson SK, Graham NAJ, Polunin NVC (2007) Appraisal of visual assessments of habitat complexity and benthic composition on coral reefs. Mar Biol 151:1069-1076

Submitted: November 27, 2014; Accepted: May 12, 2015

Proofs received from author(s): July 8, 2015 